\section{Treatment of Bleeding Gastric Varices with Tissue Adhesive (Histoacryl) in Children}

Hemorrhage from gastric varices poses a special challenge to the endoscopist, since conventional sclerotherapy has a high failure rate. It has been proposed that injection with cyanoacrylate may be the method of choice to eradicate gastric varices (1); however, to our knowledge, the use of this technique in children has not previously been reported.

Case 1. A nine-year-old boy was admitted to our unit due to his fourth episode of hematemesis caused by portal hypertension arising from a prehepatic portal vein obstruction. He had undergone eradication of esophageal varices, and had persistent large gastric varices with red spots that had bled twice during the previous 50 days, despite injection with $1 \%$ polidocanol. We decided to inject enbucrilate (Histoacryl) at the level of maximum protrusion of the varix (2). The patient has been free of bleeding for the last 43 months, and no varices were detected on follow-up endoscopies.

Case 2. A two-year-old boy was admitted to the intensive-care unit with hematemesis and hypovolemic shock requiring transfusion of $30 \mathrm{ml} / \mathrm{kg}$ body weight of whole blood. He had suffered from prehepatic portal vein obstruction, and developed large gastric varices that had bled twice during the previous six months, despite being treated with $1 \%$ polidocanol endoscopic injection each time. He was not receiving propanolol, in view of his prior

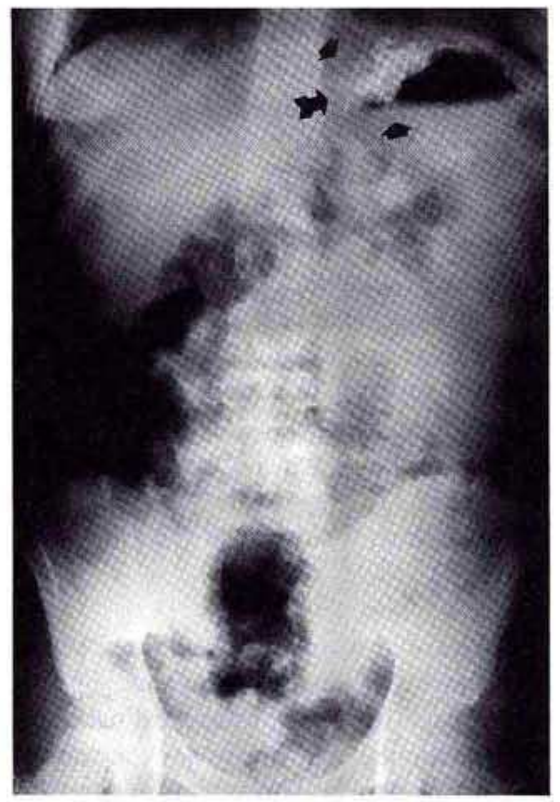

Figure 1: Plain radiograph showing the Histoacryllipiodol glue in the gastric varices of a twoyear-old boy (Case 2).

history of asthma. During the endoscopy, large, nodular (pericardial) gastric varices with red spots and two small (grade I) esophageal varices were observed. After injection of cyanoacrylate into the gastric varices, the boy has been free of bleeding during the last 36 months, and no further gastric varices are present.

Pericardial gastric and esophageal varices may behave similarly, since the former are regarded as intragastric projections of the latter (3). However, in these patients we were not able to eradicate the gastric varices after many sessions of conventional 
sclerotherapy. As described in previous reports $(4,5)$, cyanoacrylate adhesive (Histoacryl) was found to be a simple and effective method of treating bleeding gastric varices due to prehepatic portal vein destruction in the two children described, especially after the failure of other treatments.

S. Fuster, A. Costaguta, O. Tobacco Gastroenterology Center,

Sanatorio de Niños, Rosario, Argentina

\section{References}

1. Binmoeller KF, Vadeyar HJ, Soehendra N. Treatment of esophageal varices. Endoscopy 1994; 26: 42-7.

2. Soehendra N, Nam VCH, Grimm H, Kempeneers I. Endoscopic obliteration of large esophagogastric varices with bucrylate. Endoscopy 1986; 18: 25-8.

3. Sarin SK, Lahoti D, Saxena S, et al. Prevalence, classification, and natural history of gastric varices: a long-term follow-up study in 568 portal hypertensive patients. Hepatology 1992; 16: 1343-9.

4. Gimson AES, Westaby D, Williams R. Endoscopic sclerotherapy in the management of gastric variceal bleeding. J Hepatol 1991; 13: 274-8.
5. Feretis C, Dimopoulos C, Benakis P, et al. $\mathrm{N}$-butyl-2-cyanoacrylate (Histoacryl) plus sclerotherapy versus sclerotherapy alone in the treatment of bleeding esophageal varices: a randomized prospective study. Endoscopy 1995; 27: $355-7$.

Corresponding Author

S. Fuster, M.D.

Centro de Gastroenterología

Tucuman 1813 (2000)

Rosario

Argentina

Fax: + 54-41-262848 